\title{
THE LAST WORD
}

\section{COOPERATIVE R8D: A PLEA FOR PERSPECTIVE by Joel S. Marcus}

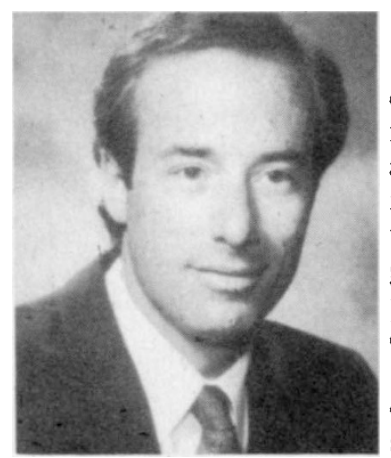

$T$ he resources available to the American biotechnology industry are valuable and finite. They must be allocated in a more efficient and rational manner due to the capital-intensive nature of biotechnology $\mathrm{R} \& \mathrm{D}$, its lengthy regulatory process, and the uncertain patent environment.

A joint research and development strategy should be spearheaded by the biotechnology industry associations. Such a strategy should then be molded into an implementation plan (including budgets) with the assistance of industry, third party experts, and the appropriate governmental agencies. These efforts will then set the stage for basic research, development of large-scale commercial production facilities, transfer of technology from the laboratory to the factory, and distribution of development money among consortia members.

Since the $1960 \mathrm{~s}$, virtually every major industrial country-except the United States-has sought to enhance its commercial competitiveness through large-scale, government-supported $\mathrm{R} \& \mathrm{D}$ projects. These programs have enabled key foreign industries to meet the United States' technological challenge. And, in many areas, such cooperative efforts have propelled foreign companies ahead of their U.S. counterparts.

Cooperative projects generally share a number of important basic characteristics:

- They are funded by government or by a governmentrelated entity together with industry.

- They are proactively supported by government, industry, and the educational sectors.

- They supersede antitrust restrictions, which have been downplayed, overlooked, or relaxed.

- They generally bring together leading companies.

- They focus primarily on significant commercial objectives.

Recently, the United States has focused on the need for such cooperative pooled R\&D in certain key industries whose worldwide markets are contracting significantly in the face of foreign competition. One such example is the Sematech consortium, proposed by the Semiconductor Industry Association to improve the competitiveness of the U.S. semiconductor industry in the world market. Instead of developing this consortium from a position of strength, however, the concept is a last-ditch attempt to save what is left of the U.S. semiconductor industry. The problem is that Japan's semiconductor industry has become far more efficient and resourceful, owing to its heavy investment in automated manufacturing equipment, meticulous maintenance procedures, and rigorous quality control. Now, finally, an attempt is being made to deal with these critical competitiveness issues.

A recent New York Times article indicated that approximately 50 different major consortia are now underway in this country. Of critical importance is whether, in the near future, they can both develop the technology and assist in the transfer of this technology to their members.

Biotechnology companies are now facing the significant challenge of profitably commercializing their innovative research and development. Public and private financings together with strategic alliance relationships have provided much needed capital. A critical problem for the U.S. biotechnology industry, however, is fragmentation. Hundreds of small companies duplicate each others' efforts, while only a handful garner sufficient sales to counterbalance their research and development expenses. Many experts have indicated that free market forces will probably force many of the smaller companies out of business; many that survive will merge or be acquired. The process will be agonizingly slow, and will take place as foreign competitors increase their expertise and world market share.

While the United States has a clear leadership role in biotechnology, it is time to carefully and thoughtfully develop our state-of-the-art biotechnology research, development, and production capabilities. This cooperative effort is needed because of the high cost of developing such advanced technology for individual companies, particularly when faced with government-subsidized overseas competition.

Such a proposal faces a number of critical organizational, financial, and legal hurdles. Joint effort among potentially competing companies is itself a major obstacle. Is cooperative $\mathrm{R} \& \mathrm{D}$ (a la Japan) possible in a country where corporate secrecy is sacrosanct? Can agreement be reached on goals and objectives? Recent experience with consortia in other industries offers no reassurance. For example, the synthetic fuels corporation was a multibillion-dollar disaster.

Commercializing technology to compete effectively in world markets is one of corporate America's most serious problems. However, unless there is a fundamental shift in the attitude of government and of American companies that have long prided themselves on doing their own product research, development, and manufacture, efficiently structured pooled R\&D will not become a commercial reality.

Since only a handful of biotechnology firms have adequate resources to fully develop and market biotech products, industry and government should marshal their resources and develop a sensible plan to provide for joint $\mathrm{R} \& \mathrm{D}$ and cost-competitive state-of-the-art production facilities, while maintaining the highest standards of quality. Unfortunately, Yankee ingenuity all-too-often falters when it comes to financing these cooperative efforts.

After witnessing foreign competition come to dominate the steel, automobile, and machine tool industries, nobody wants to see America lose its biotechnology edge. We are in a new competitive environment, and we must respond in a commercially sensible manner that looks to the longterm, not merely tomorrow.

Joel S. Marcus, Esq., is partner-in-charge: technology business group at Pettit \& Martin, 355 S. Grand Ave., Los Angeles, CA 90071. These opinions are the author's own, and are not necessarily those of Bio/Technology. 